\section{Studies in Animal Inheritance.}

A LL students of modern advances in our knowledge of heredity are familiar with Prof. W. E. Castle's experiments in modifying the hooded pattern of piebald rats by continued selection. In a recent Publication of the Carnegie Institution, No. 288 , "Studies of Heredity in Rabbits, Rats, and Mice," Prof. Castle describes the results of crossing his selected races with unmodified wild rats, in continuation of his previous work, and announces the conclusion to which he has come. "The same wild race, when its residual heredity is made fully effective by repeated crosses, brings both the plus-selected and the minus-selected hooded lines to a phenotype of common grade. This shows, contrary to my earlier opinion, that what has really happened in the case of the selected races was more largely due to residual heredity than to any change in the gene for the hooded character itself." In this paper further experiments on the breeding of English and Dutch whitespotted rabbits are also described, the results of which are generally comparable with those obtained from the hooded rats.

The magpie moth (Abraxas grossulariata) has been a favourite subject for breeding experiments since Doncaster's memorable demonstration of the sexlinked inheritance of the lacticolor colour-aberration. In a recent paper (Journal of Genetics, vol. viii., No. 4, 1919) H. Onslow describes the result of crossing with the type the variety lutea, in which the ground-colour of the wings is yellow or orange instead of creamy-white, the difference being due to a general deepening of the pigment of the scales. The iutea ground-colour is incompletely dominant over that of typical grossulariata, so that in the first hybrid generation the colours form a continuous series from white to deep orange, and a plotting of the frequency distribution gives an approximately even "chance" curve. "But the $\mathrm{F}_{2}$ generation, etc., are at once seen to give curves having more than one maximum caused by the tendency of the colour factors to segregate according to the ordinary Mendelian laws."

In the same number of the Journal of Genetics Dr. J. W. W. Harrison continues his series of papers on the hybrid Bistonine moths, dealing especially with what he calls the "stimulus of heterozygosis." His experiments strongly confirm the general belief maintained by Darwin that "cross-fertilisation is a source of strength or of stimulus to metabolic activity "; for he found that among the moths the inheritance of which he studied "the hybrid larvæ were not only emphatically more robust than those of the weaker parent, but they also surpassed in strength and vitality those of the stronger form." Hybrid caterpillars had a very low mortality rate, and they often completed their transformations in an "amazingly short period." Besides discussing the possible intra-cellular causes of these stimuli, Dr: Harrison points out how they may affect the results of breeding experiments on the size and weight factors of such animals as poultry or rabbits. "Any attempted genetic analyses for size purposes which fail to allow for heterozygotic impulses are vitiated and useless."

On the fascinating subject of sex-linked inheritance some new light may come from an extension of Dr. E. Hindle's records of the sexes of series of families of body-lice (Pediculus humanus corporis) published in the same number of the Journal of Genetics. Three types of family occur, all males, all females, or mixed in which one sex or the other may predominate. The author believes that these results suggest the existence of two types of female and two types of male. NO. 266 I, VOL. IO6]
The puzzling facts, first noted by Doncaster, respecting coat-colour and sex-inheritance in cats receive further attention and a suggested explanation in a short paper by C. C. Little (t.c., pp. $279-90)$.

G. H. C.

\section{The Site of the University of London.}

$\mathrm{W}^{\mathrm{E}}$ note with pleasure the decision arrived at by the Senate of the University of London regard. ing the Government's offer of a site at Bloomsbury. At the meeting of the Senate held on October 20 the report of the Site and Accommodation Committee was adopted, as was also, after a long discussion, the resolution of which we give the full text below. The provisos attached to the acceptance of the offer evince a capacity for keen bargaining and a business mentality not conventionally associated with an academic body. It is to be hoped that they will not in the eyes of the Government constitute an obstacle to the completion of the matter, though it is obvious that some of the conditions will prove difficult in practice. It would be a matter of keen regret if a scheme which has advanced so far should come to grief over any points of detail.

The text of the resolution is as follows:

"That his Majesty's Government be informed that the Senate are prepared to accept the offer made in Mr. Fisher's letter of April 7, I920, to the Chancellor of the site therein described, gratis and in perpetuity, on the terms as regards the maintenance, rates, etc., of the University headciuarters buildings laid down in the Treasury Minutes of February 16 and July 13, 1899 , and in Mr. Fisher's letters of June 26 , September 24, and October 6, 1920, to the Vice-Chancellor, provided :

"(I) That such grant for maintenance, rates, etc., shall not be counted as a portion of the grants made to universities for educational purposes.

"(2) That the allocation of the site between the various buildings to be erected thereon shall be at the sole discretion of the Senate of the University.

"(3) That the University shall retain and King's College shall retain full nossession of their present sites and buildings under the conditions under which they now hold them until such time as the new buildings are ready for occupation and are free from debt.

"(4) That the buildings to be erected for the University headquarters shall be as regards dimensions and design, in accordance with plans to be agreed upon between the Senate and his Majesty's Treasury, and shall afford not less than so per cent. more floorspace than is now allocated in the buildings at South Kensington for the separate use of the University.

"(5) That the terms of the removal of King's College from the Strand to the Bloomsbury site shall be a matter of subsequent negotiation between his Maiestv's Government, the Council of King's College, and the Senate of the University, and that an agreement shall be concluded between the said parties.

"And that the Senate, in accepting subject to the above conditions, the Government's offer of a site in Bloomsbury, assume that the offer does not incidentally involve a policy of curtailing the development of the work of those colleges and schools of the University which are not now, nor in the future will be, situated in the neighbourhood of the Bloomsbury site, and that these institutions will not receive less favourable consideration at the hands of the Government than would otherwise have been the case." 